\title{
A comparison of pectoralis versus lumbar skeletal muscle indices for defining sarcopenia in diffuse large B-cell lymphoma - two are better than one
}

\author{
Se-Il Go ${ }^{1, *}$, Mi Jung Park ${ }^{2, *}$, Haa-Na Song ${ }^{3}$, Hoon-Gu Kim ${ }^{1,4}$, Myoung Hee Kang ${ }^{1,4}$, \\ Jung Hun Kang ${ }^{3,4}$, Hye Ree Kim ${ }^{3}$ and Gyeong-Won Lee ${ }^{3,4}$ \\ ${ }^{1}$ Division of Hematology-Oncology, Department of Internal Medicine, Gyeongsang National University Changwon Hospital, \\ Gyeongsang National University College of Medicine, Changwon, Republic of Korea \\ ${ }^{2}$ Department of Radiology, Gyeongsang National University Hospital, Gyeongsang National University College of Medicine, \\ Jinju, Republic of Korea \\ ${ }^{3}$ Division of Hematology-Oncology, Department of Internal Medicine, Gyeongsang National University Hospital, Gyeongsang \\ National University College of Medicine, Jinju, Republic of Korea \\ ${ }^{4}$ Institute of Health Science, Gyeongsang National University College of Medicine, Jinju, Republic of Korea \\ *These authors have contributed equally to this work \\ Correspondence to: Gyeong-Won Lee, email: brightree24@gmail.com \\ Keywords: sarcopenia, diffuse large B-cell lymphoma, muscle, drug toxicity, prognosis \\ Received: February 04, $2017 \quad$ Accepted: February 28, $2017 \quad$ Published: March 24, 2017 \\ Copyright: Go et al. This is an open-access article distributed under the terms of the Creative Commons Attribution License 3.0 \\ (CC BY 3.0), which permits unrestricted use, distribution, and reproduction in any medium, provided the original author and source \\ are credited.
}

\section{ABSTRACT}

Backgrounds: Sarcopenia is known to be associated with poor clinical outcome in patients with diffuse large B-cell lymphoma (DLBCL). There is no consensus concerning the optimal method to define sarcopenia in DLBCL.

Methods: We retrospectively reviewed 193 DLBCL patients treated with rituximab plus cyclophosphamide, doxorubicin, vincristine, and prednisone (R-CHOP) therapy. Sarcopenia was classified by the region where the pretreatment skeletal muscle index (SMI) was measured.

Results: Both the sarcopenia-L3 and sarcopenia-pectoralis muscle (PM) groups had increased incidences of severe treatment-related toxicities and treatment discontinuation compared with the non-sarcopenia-L3 and non-sarcopenia-PM groups, respectively. The sarcopenia-L3 and non-sarcopenia-L3 groups had 5-year overall survival (OS) rates of $40.5 \%$ and $67.8 \%(p<0.001)$, respectively. The sarcopenia-PM and non-sarcopenia-PM groups had 5 -year OS rates of $35.9 \%$ and $69.0 \%(p<0.001)$, respectively. When the sarcopenia-L3 alone and sarcopenia-PM alone groups were compared, there were no differences in baseline characteristics, treatment toxicity, or survival. In multivariate analysis, when compared with the non-sarcopenia-both group, OS was significantly worse in the sarcopenia-both group (HR, 2.480; 95\% CI, 1.284-4.792; $p=0.007$ ), but not in patients with either sarcopenia-L3 alone or sarcopenia-PM alone $(p=0.151)$.

Conclusions: L3- and PM-SMIs are equally useful to define sarcopenia, which is related to intolerance to R-CHOP therapy and to worse survival in patients with DLBCL. More prognostic information can be obtained when these two SMIs are combined to define sarcopenia.

\section{INTRODUCTION}

The introduction of rituximab into front-line therapy has dramatically improved the clinical outcome of patients with diffuse large B-cell lymphoma (DLBCL). Compared with conventional chemotherapy, rituximab-based regimens such as R-CHOP (rituximab plus cyclophosphamide, doxorubicin, vincristine, and prednisone) resulted in an 
increased complete response (CR) rate and prolonged survival, without a significant increase in toxicity, in patients with DLBCL [1-4]. However, it is debatable whether frail patients, who have an increased risk of treatment complications, benefit from R-CHOP therapy because pivotal randomized trials excluded these populations from the analysis $[1,2,4]$. Furthermore, DLBCL patients with significant comorbidities or poor performance status (PS) are intolerant to R-CHOP therapy and have poor prognosis, mainly due to treatment-related toxicities and frequent cessation of treatment [5-7]. Recent studies have suggested that alternative therapeutic strategies to the standard R-CHOP regimen, such as dose modification, reduction of chemotherapy cycles, and replacement of anthracycline with other agents, showed a favorable toxicity profile with acceptable survival rates in frail patients with DLBCL [812]. Therefore, clinical markers to identify patients who are intolerant to standard R-CHOP therapy need to be developed for individualized therapy in DLBCL patients.

Cancer cachexia is a multifactorial syndrome related to systemic inflammation and adverse outcomes in patients with cancer $[13,14]$. Many studies have reported that inflammatory markers and other biomarkers for cancer cachexia can help to predict the prognosis and to improve the performance of prognostic indices in DLBCL [1521]. Additionally, sarcopenia is known to be associated with an increased risk of treatment-related toxicity and a worse survival outcome in various solid tumors [22-26]. Unfavorable aspects of sarcopenia have also been evaluated in patients with DLBCL. In a French study of 82 elderly DLBCL patients treated with an R-CHOP or R-miniCHOP regimen, sarcopenic patients had a higher revised International Prognostic Index (R-IPI), more frequent discontinuation of treatment, and a higher risk of death than did non-sarcopenic patients [27]. In a Japanese study of 207 DLBCL patients who received R-CHOP or its derivative regimen, male - but not female - sarcopenic patients had worse progression-free survival (PFS) compared with non-sarcopenic patients [28]. These two previous studies used the L3 skeletal muscle index (L3-SMI), measured by computed tomography (CT), to determine sarcopenia. Recently, we demonstrated that sarcopenia, determined by pectoralis muscle SMI (PM-SMI), was also strongly associated with intolerance to treatment and with poor prognosis in DLBCL patients who were treated with the standard R-CHOP regimen [29]. In addition, we suggested that the addition of sarcopenic status to IPI components can improve the predictive power of IPI [29].

In this study, given the uncertainty about the optimal SMI to define clinically meaningful sarcopenia in DLBCL, we compared the characteristics and clinical outcome between sarcopenic patients determined by L3SMI and those determined by PM-SMI who were treated with standard front-line R-CHOP therapy. Furthermore, the synergistic role of L3- and PM-SMIs as prognostic markers was also investigated.

\section{RESULTS}

\section{Patient population and characteristics}

In total, 193 patients were included in the final analysis. There were 116 patients in the non-sarcopeniaboth group. Of the remaining 77 patients with some form of sarcopenia, 22, 30, and 25 patients were classified into the sarcopenia-both, sarcopenia-L3 alone, and sarcopenia-PM alone groups, respectively. When the sarcopenic status was dichotomized according to the type of SMI, 52 and 141 patients comprised the sarcopenia-L3 and non-sarcopenia-L3 groups, and 55 and 138 patients comprised the sarcopenia-PM and non-sarcopenia-PM groups, respectively. There were no differences in L3-SMI between non-sarcopenia-both and sarcopenia-PM alone groups $(p=0.132)$ and in PMSMI between non-sarcopenia-both and sarcopenia-L3 alone groups $(p=0.293)$. Both L3- and PM-SMIs were significantly and weakly associated with $\mathrm{BMI}\left(\mathrm{R}^{2}=\right.$ $0.29, p<0.001$ and $\mathrm{R}^{2}=0.04, p=0.003$, respectively; Figure 1).

Baseline characteristics of patients are presented in Table 1. Compared with the non-sarcopenia-L3 group, the sarcopenia-L3 group was associated with old age, poor PS, B-symptoms, advanced Ann Arbor stage, higher IPI, R-IPI, and National Comprehensive Cancer Network-IPI (NCCN-IPI), and hypoalbuminemia. The sarcopenia-PM group also had the adverse clinical characteristics observed in the sarcopenia-L3 group, except PS and Ann Arbor stage. When the sarcopenia-L3 alone and sarcopenia-PM alone groups were directly compared, there were no differences in any of the baseline characteristics.

It was found that the greater the sarcopenic status, the worse the clinical status of patients. Considering baseline characteristics such as age, PS, tumor stage, and prognostic indices, the sarcopenia-both group had the worst clinical features, while the sarcopenia-L3/ PM alone group had intermediate clinical features and the non-sarcopenia-both group had the most favorable clinical features.

\section{Treatment-related toxicity and compliance}

Comparisons of toxicity and compliance for R-CHOP therapy between groups are described in Table 2. Compared with the non-sarcopenia-L3 group, the sarcopenia-L3 group had more frequent grade 3 anemia (28.9\% vs. $14.9 \%, p=0.027)$, grade $3-4$ (34.6\% vs. $18.4 \%, p=0.017)$ and grade $4(23.1 \%$ vs. $10.6 \%, p=$ $0.027)$ thrombocytopenia, grade $4-5$ non-hematologic toxicity $(21.2 \%$ vs. $5.7 \%, p=0.001)$, TRM $(23.1 \%$ vs. $3.6 \%, p<0.001)$, and treatment discontinuation (34.6\% vs. $13.5 \%, p=0.001)$. Similarly, the sarcopeniaPM group had more frequent grade 3 anemia (38.3\% 
Table 1: Patients' characteristics and treatment response

\begin{tabular}{|c|c|c|c|c|c|c|c|}
\hline & \multirow{2}{*}{$\begin{array}{c}\text { Sarcopenia- } \\
\text { both } \\
(n=22)\end{array}$} & \multicolumn{2}{|c|}{ Sarcopenia-L3/PM alone $(n=55)$} & \multirow{2}{*}{$\begin{array}{c}\text { Non- } \\
\text { sarcopenia- } \\
\text { both } \\
(\mathrm{n}=116)\end{array}$} & \multirow[b]{2}{*}{$\boldsymbol{P}^{\dagger}$} & \multirow[b]{2}{*}{$P$} & \multirow[b]{2}{*}{$P_{\text {trend }} \S$} \\
\hline & & L3 alone $(n=30)$ & $\begin{array}{l}\text { PM alone } \\
\quad(n=25)\end{array}$ & & & & \\
\hline Age, years & & & & & 0.001 & 0.017 & 0.002 \\
\hline Median & 68 & 66 & 65 & 58.5 & & & \\
\hline Range & $47-81$ & $27-86$ & $24-76$ & $21-82$ & & & \\
\hline Sex & & & & & 0.113 & 0.805 & 0.243 \\
\hline Male & $16(72.7)$ & $19(63.3)$ & $12(48.0)$ & $65(56.0)$ & & & \\
\hline Female & $6(27.3)$ & $11(36.7)$ & $13(52.0)$ & $51(44.0)$ & & & \\
\hline ECOG PS & & & & & $<0.001$ & 0.056 & 0.001 \\
\hline $0-1$ & $11(50.0)$ & $17(56.7)$ & $18(72.0)$ & $94(81.0)$ & & & \\
\hline $2-3$ & $11(50.0)$ & $13(43.3)$ & $7(28.0)$ & $22(19.0)$ & & & \\
\hline B-symptoms & & & & & 0.037 & 0.003 & 0.001 \\
\hline Absent & $12(54.5)$ & $24(80.0)$ & $18(72.0)$ & $99(85.3)$ & & & \\
\hline Present & $10(45.5)$ & $6(20.0)$ & $7(28.0)$ & $17(14.7)$ & & & \\
\hline Bulky disease & & & & & 0.141 & 0.058 & 0.034 \\
\hline Non-bulky & $15(68.2)$ & $25(83.3)$ & $20(80.0)$ & $101(87.1)$ & & & \\
\hline Bulky & $7(31.8)$ & $5(16.7)$ & $5(20.0)$ & $15(12.9)$ & & & \\
\hline Ann Arbor stage & & & & & 0.015 & 0.158 & 0.015 \\
\hline I - II & $5(22.7)$ & $11(36.7)$ & $12(48.0)$ & $59(50.9)$ & & & \\
\hline III - IV & $17(77.3)$ & $19(63.3)$ & $13(52.0)$ & $57(49.1)$ & & & \\
\hline $\begin{array}{l}\text { Extranodal } \\
\text { involvement }\end{array}$ & & & & & 0.012 & 0.092 & 0.008 \\
\hline $0-1$ site & $12(54.5)$ & $17(56.7)$ & $16(64.0)$ & $89(76.7)$ & & & \\
\hline$>1$ site & $10(45.5)$ & $13(43.3)$ & $9(36.0)$ & $27(23.3)$ & & & \\
\hline LDH & & & & & 0.153 & 0.454 & 0.168 \\
\hline Normal & $8(36.4)$ & $10(33.3)$ & $10(40.0)$ & $55(47.4)$ & & & \\
\hline Elevated & $14(63.6)$ & $20(66.7)$ & $15(60.0)$ & $61(52.6)$ & & & \\
\hline IPI & & & & & 0.003 & 0.006 & $<0.001$ \\
\hline $\begin{array}{l}\text { Low to low- } \\
\text { intermediate }\end{array}$ & $6(27.3)$ & $15(50.0)$ & $13(52.0)$ & $77(66.4)$ & & & \\
\hline $\begin{array}{l}\text { High-intermediate } \\
\text { to high }\end{array}$ & $16(72.7)$ & $15(50.0)$ & $12(48.0)$ & $39(33.6)$ & & & \\
\hline R-IPI & & & & & 0.003 & 0.014 & $<0.001$ \\
\hline Very good & $0(0.0)$ & $2(6.7)$ & $3(12.0)$ & $25(21.6)$ & & & \\
\hline Good & $6(27.3)$ & $13(43.3)$ & $10(40.0)$ & $52(44.8)$ & & & \\
\hline Poor & $16(72.7)$ & $15(50.0)$ & $12(48.0)$ & $39(33.6)$ & & & \\
\hline
\end{tabular}

(Continued) 


\begin{tabular}{|c|c|c|c|c|c|c|c|}
\hline & \multirow{2}{*}{$\begin{array}{l}\text { Sarcopenia- } \\
\text { both } \\
(\mathbf{n}=\mathbf{2 2})\end{array}$} & \multicolumn{2}{|c|}{ Sarcopenia-L3/PM alone $(n=55)$} & \multirow{2}{*}{$\begin{array}{l}\text { Non- } \\
\text { sarcopenia- } \\
\text { both } \\
(\mathrm{n}=116)\end{array}$} & \multirow[b]{2}{*}{$\boldsymbol{P}^{\dagger}$} & \multirow[b]{2}{*}{$P$} & \multirow[b]{2}{*}{$\boldsymbol{P}_{\text {trend }} \S$} \\
\hline & & L3 alone $(\mathrm{n}=\mathbf{3 0})$ & $\begin{array}{l}\text { PM alone } \\
\quad(n=25)\end{array}$ & & & & \\
\hline NCCN-IPI & & & & & 0.011 & 0.013 & 0.002 \\
\hline $\begin{array}{l}\text { Low to low- } \\
\text { intermediate }\end{array}$ & $5(22.7)$ & $13(43.3)$ & $11(44.0)$ & $67(57.8)$ & & & \\
\hline $\begin{array}{l}\text { High-intermediate } \\
\text { to high }\end{array}$ & $17(77.3)$ & $17(56.7)$ & $14(56.0)$ & $49(42.2)$ & & & \\
\hline Albumin & & & & & $<0.001$ & $<0.001$ & $<0.001$ \\
\hline Normal & $6(27.3)$ & $18(60.0)$ & $12(48.0)$ & $94(81.0)$ & & & \\
\hline Hypoalbuminemia & $16(72.7)$ & $12(40.0)$ & $13(52.0)$ & $22(19.0)$ & & & \\
\hline Treatment response & & & & & 0.006 & 0.002 & $<0.001$ \\
\hline $\mathrm{CR}$ & $11(50.0)$ & $20(66.7)$ & $16(64.0)$ & $99(85.3)$ & & & \\
\hline $\mathrm{PR}, \mathrm{NR} / \mathrm{SD}$, or $\mathrm{PD}$ & $7(31.8)$ & $9(30.0)$ & $6(24.0)$ & $12(10.3)$ & & & \\
\hline Not available* & $4(18.2)$ & $1(3.3)$ & $3(12.0)$ & $5(4.3)$ & & & \\
\hline
\end{tabular}

Data are presented as number of patients (\%) except age.

There were no statistical differences between sarcopenia-L3 alone and -PM alone groups (data not shown).

Abbreviations: $\mathrm{PM}=$ pectoralis muscle, ECOG PS = Eastern Cooperative Oncology Group performance status, $\mathrm{LDH}=$ lactate dehydrogenase, IPI = International Prognostic Index, R-IPI = revised International Prognostic Index, NCCN-IPI = National Comprehensive Cancer Network International Prognostic Index, $\mathrm{CR}=$ complete response, $\mathrm{PR}=$ partial response, $\mathrm{NR}=$ no response, $\mathrm{SD}=$ stable disease, $\mathrm{PD}=$ progressive disease.

*Information for treatment response was not available in 13 patients due to the following reasons: early discontinuation of treatment due to treatment toxicity after the first cycle of chemotherapy (6 patients); patient's own will to withdraw the treatment ( 5 patients); and loss of follow-up ( 2 patients).

$\dagger$ Comparing sarcopenia-L3 (sarcopenia-both + sarcopenia-L3 alone) with non-sarcopenia-L3 (others).

tComparing sarcopenia-PM (sarcopenia-both + sarcopenia-PM alone) with non-sarcopenia-PM (others).

$\S$ Comparing sarcopenia-both with sarcopenia-L3/PM alone and non-sarcopenia-both.
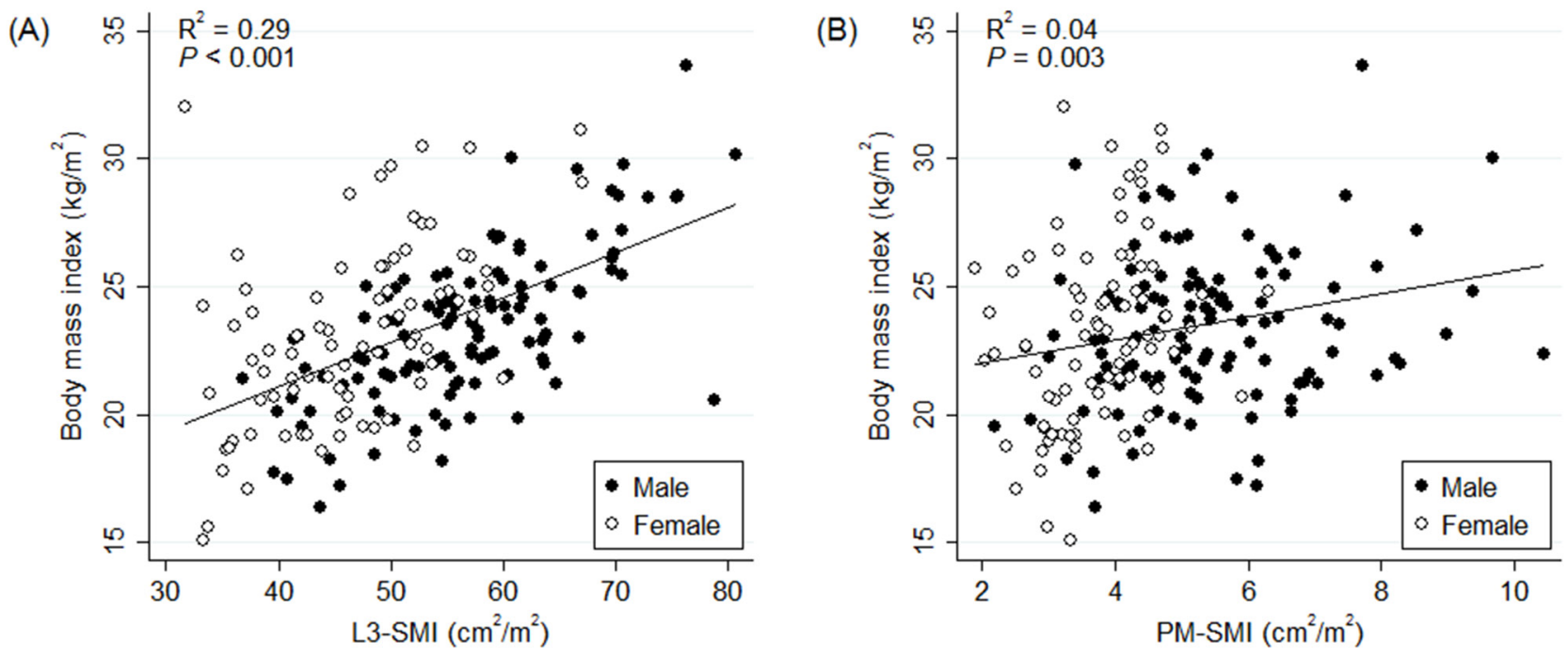

Figure 1: Correlation between body mass index and (A) L3-SMI and (B) PM-SMI. Abbreviations: L3-SMI = L3 skeletal muscle index, PM-SMI = pectoralis muscle skeletal muscle index. 
Table 2: Comparison of toxicity and compliance for R-CHOP therapy according to sarcopenic status

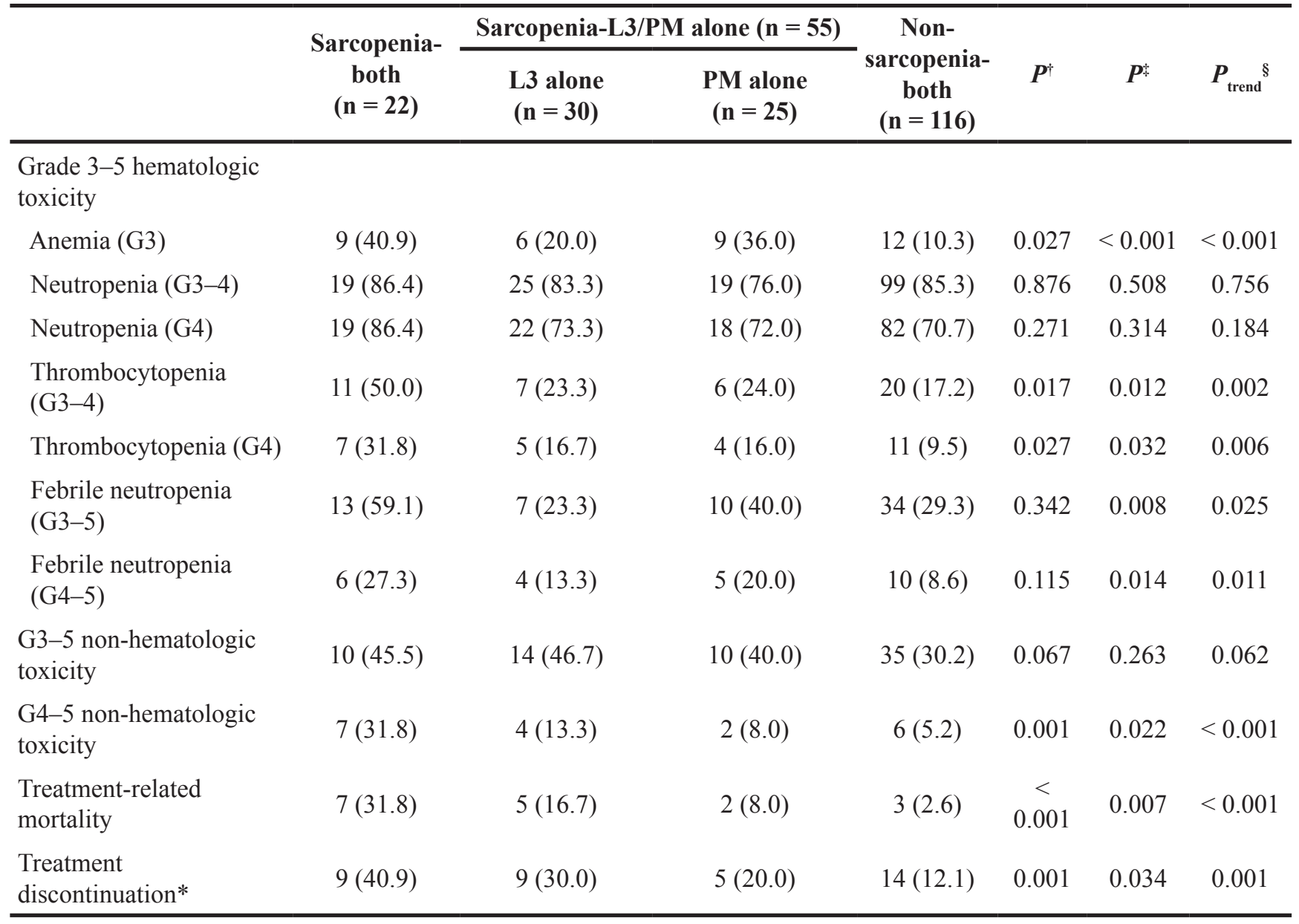

Data are presented as number of patients having an event (\%).

There were no statistical differences between sarcopenia-L3 alone and -PM alone groups (data not shown).

*Three patients discontinued the treatment after 3 cycles of R-CHOP due to early disease progression.

$\dagger$ Comparing sarcopenia-L3 (sarcopenia-both + sarcopenia-L3 alone) with non-sarcopenia-L3 (others).

\$Comparing sarcopenia-PM (sarcopenia-both + sarcopenia-PM alone) with non-sarcopenia-PM (others).

$\S$ Comparing sarcopenia-both with sarcopenia-L3/PM alone and non-sarcopenia-both.

vs. $12.3 \%, p<0.001)$, grade $3-4(36.2 \%$ vs. $18.5 \%$, $p=0.012)$ and grade $4(23.4 \%$ vs. $11.0 \%, p=0.032)$ thrombocytopenia, grade $4-5$ non-hematologic toxicity $(19.2 \%$ vs. $6.9 \%, p=0.022)$, TRM $(19.2 \%$ vs. $5.5 \%, p=$ $0.007)$, and treatment discontinuation ( $29.8 \%$ vs. $15.8 \%$, $p=0.034$ ), in addition to febrile neutropenia (grade $3-4,48.9 \%$ vs. $28.1 \%, p=0.008$; grade $4-5,23.4 \%$ vs. $9.6 \%, p=0.014)$, compared to the non-sarcopenia-PM group. However, there were statistically no differences in treatment-related toxicity or treatment discontinuation between the sarcopenia-L3 alone and sarcopenia-PM alone groups.

The sarcopenia-both group was extremely intolerant to R-CHOP therapy. The rates of grade 3 anemia $(40.9 \%)$, grade $3-4(50.0 \%)$ and grade $4(31.8 \%)$ thrombocytopenia, grade 3-5 (59.1\%) and grade 4-5 (27.3\%) febrile neutropenia, grade 4-5 non-hematologic toxicity (31.8\%), TRM (31.8\%), and treatment discontinuation (40.9\%) were highest in the sarcopenia-both group, followed by the sarcopenia-L3/PM alone group and the non-sarcopeniaboth group.

\section{Treatment response}

Data for treatment response were available for 180 of 193 patients (Table 1). In the analysis of all 193 patients, the CR rate was much lower in the sarcopeniaboth group than in the sarcopenia-L3/PM alone group and in the non-sarcopenia-both group (50.0\% vs. $65.5 \%$ vs. $85.3 \%, p<0.001)$. When treatment response was assessed in 159 patients, excluding 34 patients who discontinued treatment due to reasons other than disease progression, 
the difference in the $\mathrm{CR}$ rate was still significant between the sarcopenia-both, sarcopenia-L3/PM alone, and nonsarcopenic groups, but the significance was lower $(71.4 \%$ vs. $83.3 \%$ vs. $92.2 \%, p=0.043)$. There was no difference in the CR rate between the sarcopenia-L3 alone and sarcopenia-PM alone groups $(p=0.511)$.

\section{Survival}

The median follow-up durations were 58.4 and 52.4 months in all patients and in survivors, respectively. The sarcopenia-L3 group had worse PFS (5-year PFS, $39.8 \%$ vs. $64.9 \%, p<0.001$; Figure $2 \mathrm{~A}$ ) and OS (5-year OS, $40.5 \%$ vs. $67.8 \%, p<0.001$; Figure $2 \mathrm{~B}$ ) than did the non-sarcopenia-L3 group. The sarcopenia-PM group also had longer PFS (5-year PFS, $35.5 \%$ vs. $66.0 \%, p<0.001$; Figure 2C) and OS (5-year OS, 35.9\% vs. 69.0\%, $p<$ 0.001 ; Figure 2D), compared with the non-sarcopenia-PM group.

When the sarcopenia-L3 alone and sarcopenia-PM alone groups were compared, there were no differences in PFS ( $p=0.927$; Figure 3A) or OS ( $p=0.996$; Figure $3 B)$. Given the very similar survival curves of the
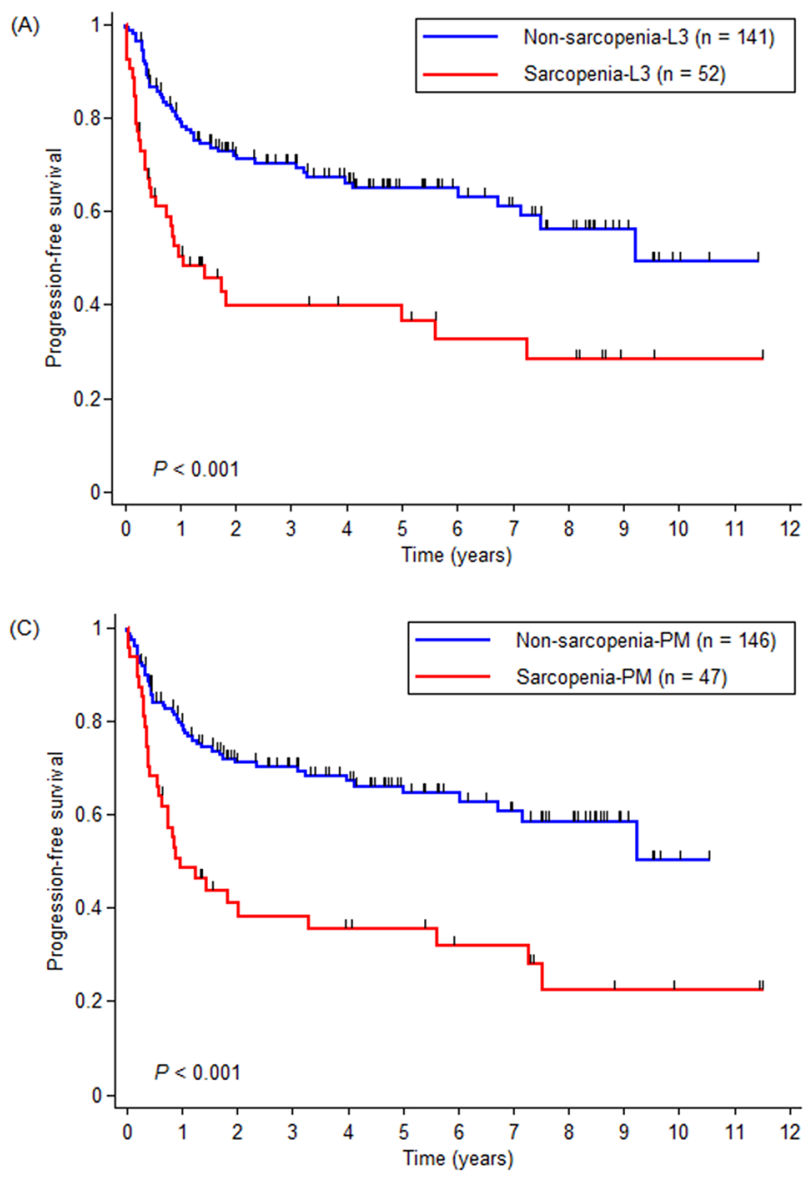

sarcopenia-L3 alone and sarcopenia-PM alone groups, the sarcopenia-L3/PM alone group, which comprised these two groups, was used in further survival analyses. The sarcopenia-both group had the worst PFS (5-year PFS, $19.1 \%$ vs. $52.4 \%$ vs. $68.5 \%, p<0.001$; Figure 3 C) and OS (5-year OS, $18.2 \%$ vs. $54.5 \%$ vs. $71.5 \%, p<0.001$; Figure 3D), followed by the sarcopenia L3/PM alone group and the non-sarcopenia-both group.

In multivariate analysis adjusted for B-symptoms, albumin status, and five factors of the IPI, having both types of sarcopenia (i.e., the sarcopenia-both group but not the sarcopenia-L3/PM alone group), was one of the independent factors for worse PFS (HR $=2.166 ; 95 \%$ CI: $1.146-4.095 ; p=0.017)$ and $\mathrm{OS}(\mathrm{HR}=2.480 ; 95 \%$ CI: $1.284-4.792 ; p=0.007)$, compared with the nonsarcopenia-both group (Table 3 ).

\section{DISCUSSION}

Cancer-associated cachexia consumes skeletal muscle in cancer patients through the complex mechanisms. An experimental study suggested that
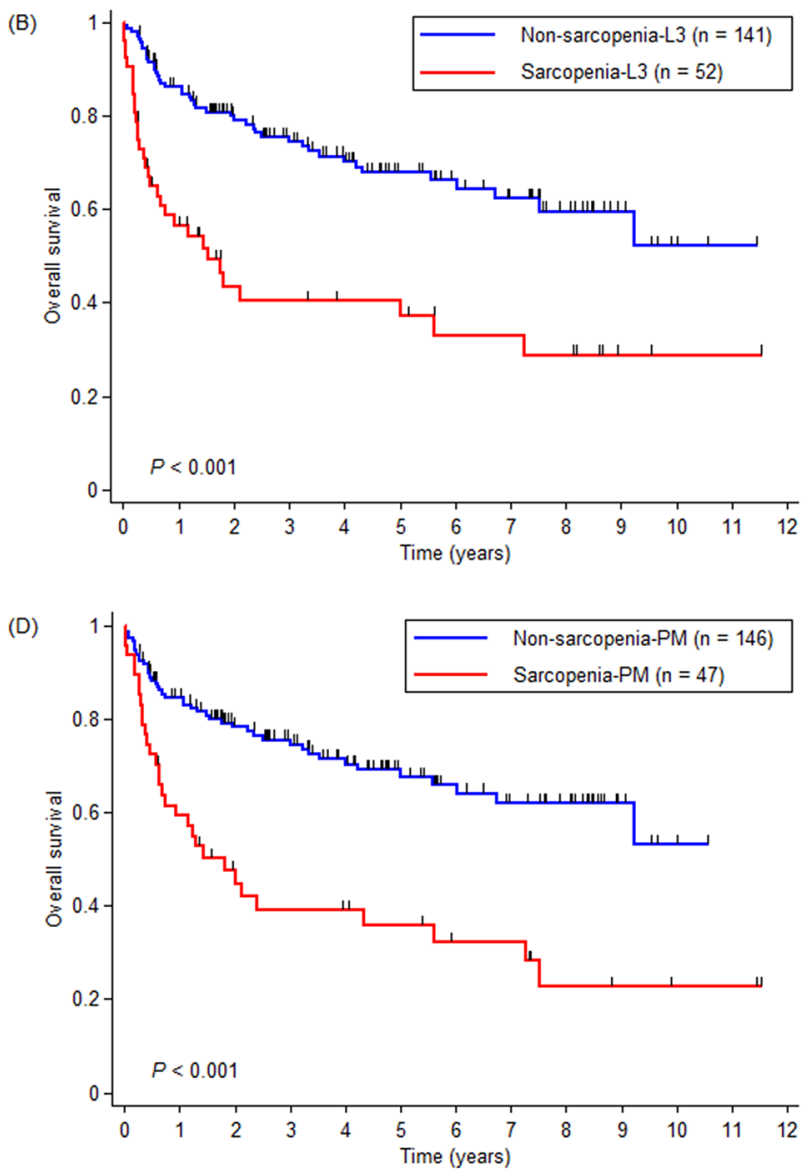

Figure 2: Kaplan-Meier curves for (A and C) progression-free survival and (B and D) overall survival (OS) according to sarcopenic status determined by L3-SMI and by PM-SMI, respectively. Abbreviations: L3-SMI = L3 skeletal muscle index, PM-SMI = pectoralis muscle skeletal muscle index. 
Table 3: Univariate and multivariate analyses for PFS and OS

\begin{tabular}{|c|c|c|c|c|c|c|c|c|c|c|c|c|}
\hline \multirow[t]{3}{*}{ Factor } & \multicolumn{6}{|c|}{ PFS } & \multicolumn{6}{|c|}{ OS } \\
\hline & \multicolumn{3}{|c|}{ Univariate } & \multicolumn{3}{|c|}{ Multivariate } & \multicolumn{3}{|c|}{ Univariate } & \multicolumn{3}{|c|}{ Multivariate } \\
\hline & HR & $95 \%$ CI & $p$ & HR & $95 \%$ CI & $p$ & HR & $95 \%$ CI & $p$ & HR & $95 \%$ CI & $p$ \\
\hline \multicolumn{13}{|l|}{ Age, years } \\
\hline$\leq 60$ & Ref. & & & Ref. & & & Ref. & & & Ref. & & \\
\hline$>60$ & 3.092 & $\begin{array}{c}1.878- \\
5.089\end{array}$ & $\begin{array}{c}< \\
0.001\end{array}$ & 1.826 & $1.056-3.159$ & 0.031 & 3.246 & $1.925-5.475$ & $\begin{array}{c}< \\
0.001\end{array}$ & 1.962 & $\begin{array}{l}1.108- \\
3.476\end{array}$ & 0.021 \\
\hline \multicolumn{13}{|l|}{ Sex } \\
\hline Male & Ref. & & & & & & Ref. & & & & & \\
\hline Female & 0.803 & $\begin{array}{c}0.514- \\
1.256\end{array}$ & 0.337 & & & & 0.802 & $0.502-1.281$ & 0.355 & & & \\
\hline \multicolumn{13}{|l|}{ ECOG PS } \\
\hline $0-1$ & Ref. & & & Ref. & & & Ref. & & & Ref. & & \\
\hline $2-3$ & 3.525 & $\begin{array}{c}2.255- \\
5.511\end{array}$ & $\begin{array}{c}< \\
0.001\end{array}$ & 2.023 & $1.205-3.396$ & 0.008 & 3.883 & $2.434-6.196$ & $\begin{array}{c}< \\
0.001\end{array}$ & 2.145 & $\begin{array}{c}1.248- \\
3.687\end{array}$ & 0.006 \\
\hline \multicolumn{13}{|l|}{ B-symptoms } \\
\hline Absent & Ref. & & & Ref. & & & Ref. & & & Ref. & & \\
\hline Present & 2.607 & $\begin{array}{l}1.639- \\
4.149\end{array}$ & $\begin{array}{c}< \\
0.001\end{array}$ & 1.241 & $0.724-2.125$ & 0.432 & 2.589 & $1.596-4.199$ & $\begin{array}{c}< \\
0.001\end{array}$ & 1.175 & $\begin{array}{c}0.679- \\
2.032\end{array}$ & 0.565 \\
\hline \multicolumn{13}{|l|}{ Bulky disease } \\
\hline Non-bulky & Ref. & & & & & & Ref. & & & & & \\
\hline Bulky & 0.744 & $\begin{array}{c}0.393- \\
1.410\end{array}$ & 0.365 & & & & 0.827 & $0.435-1.574$ & 0.563 & & & \\
\hline \multicolumn{13}{|l|}{ Ann Arbor stage } \\
\hline I - II & Ref. & & & Ref. & & & Ref. & & & Ref. & & \\
\hline III - IV & 3.905 & $\begin{array}{c}2.342- \\
6.510\end{array}$ & $\begin{array}{c}< \\
0.001\end{array}$ & 2.192 & $1.125-4.272$ & 0.021 & 3.665 & $2.162-6.213$ & $\begin{array}{c}< \\
0.001\end{array}$ & 2.094 & $\begin{array}{c}1.041- \\
4.212\end{array}$ & 0.038 \\
\hline \multicolumn{13}{|l|}{$\begin{array}{l}\text { Extranodal } \\
\text { involvement }\end{array}$} \\
\hline $0-1$ site & Ref. & & & Ref. & & & Ref. & & & Ref. & & \\
\hline$>1$ site & 4.213 & $\begin{array}{c}2.690- \\
6.599\end{array}$ & $\begin{array}{c}< \\
0.001\end{array}$ & 1.816 & $1.018-3.239$ & 0.043 & 3.939 & $2.465-6.295$ & $\begin{array}{c}< \\
0.001\end{array}$ & 1.715 & $\begin{array}{c}0.929- \\
3.166\end{array}$ & 0.084 \\
\hline \multicolumn{13}{|l|}{ LDH } \\
\hline Normal & Ref. & & & Ref. & & & Ref. & & & Ref. & & \\
\hline Elevated & 2.596 & $\begin{array}{c}1.596- \\
4.221\end{array}$ & $\begin{array}{c}< \\
0.001\end{array}$ & 1.454 & $0.845-2.501$ & 0.176 & 2.882 & $1.720-4.829$ & $\begin{array}{c}< \\
0.001\end{array}$ & 1.702 & $\begin{array}{c}0.955- \\
3.032\end{array}$ & 0.071 \\
\hline \multicolumn{13}{|l|}{ Albumin } \\
\hline Normal & Ref. & & & Ref. & & & Ref. & & & Ref. & & \\
\hline Hypoalbuminemia & 3.281 & $\begin{array}{c}2.119- \\
5.082\end{array}$ & $\begin{array}{c}< \\
0.001\end{array}$ & 1.345 & $0.810-2.234$ & 0.252 & 3.873 & $2.445-6.134$ & $\begin{array}{c}< \\
0.001\end{array}$ & 1.526 & $\begin{array}{c}0.896- \\
2.600\end{array}$ & 0.120 \\
\hline \multicolumn{13}{|l|}{ BMI } \\
\hline Normal to obese & Ref. & & & & & & Ref. & & & & & \\
\hline Underweight & 1.553 & $\begin{array}{c}0.676- \\
3.569\end{array}$ & 0.300 & & & & 1.749 & $0.759-4.033$ & 0.190 & & & \\
\hline
\end{tabular}

(Continued) 


\begin{tabular}{|c|c|c|c|c|c|c|c|c|c|c|c|c|}
\hline \multirow[t]{3}{*}{ Factor } & \multicolumn{6}{|c|}{ PFS } & \multicolumn{6}{|c|}{ OS } \\
\hline & \multicolumn{3}{|c|}{ Univariate } & \multicolumn{3}{|c|}{ Multivariate } & \multicolumn{3}{|c|}{ Univariate } & \multicolumn{3}{|c|}{ Multivariate } \\
\hline & HR & $95 \% \mathrm{CI}$ & $p$ & HR & $95 \%$ CI & $p$ & HR & $95 \%$ CI & $p$ & HR & $95 \%$ CI & $p$ \\
\hline \multicolumn{13}{|l|}{ Sarcopenia status } \\
\hline $\begin{array}{l}\text { Non-sarcopenia- } \\
\text { both }\end{array}$ & Ref. & & & Ref. & & & Ref. & & & Ref. & & \\
\hline $\begin{array}{l}\text { Sarcopenia-L3/ } \\
\text { PM alone }\end{array}$ & 1.785 & $\begin{array}{c}1.080- \\
2.951\end{array}$ & 0.024 & 1.401 & $0.820-2.393$ & 0.218 & 1.927 & $1.134-3.275$ & 0.015 & 1.512 & $\begin{array}{l}0.860- \\
2.658\end{array}$ & 0.151 \\
\hline Sarcopenia-both & 4.836 & $\begin{array}{c}2.764- \\
8.462\end{array}$ & $\begin{array}{c}< \\
0.001\end{array}$ & 2.166 & $1.146-4.095$ & 0.017 & 5.808 & $3.265-10.332$ & $\begin{array}{c}< \\
0.001\end{array}$ & 2.480 & $\begin{array}{c}1.284- \\
4.792\end{array}$ & 0.007 \\
\hline
\end{tabular}

Abbreviations: $\mathrm{PFS}=$ progression-free survival, $\mathrm{OS}=$ overall survival, $\mathrm{HR}=$ hazard ratio, $\mathrm{CI}=$ confidence interval, $\mathrm{ECOG}$ $\mathrm{PS}=$ Eastern Cooperative Oncology Group performance status, $\mathrm{LDH}=$ lactate dehydrogenase, $\mathrm{BMI}=$ body mass index, $\mathrm{PM}=$ pectoralis muscle.

adipose triglyceride lipase leads to sarcopenia by causing complete loss of white adipose tissue [14]. Another study reported that IL-6 mediates sarcopenia in cancerassociated cachexia by activating FOXO3 and atrogin [30]. Previous clinical studies reported that sarcopenia leads to higher drug exposure, which results in an increased incidence of dose-limiting toxicities in patients
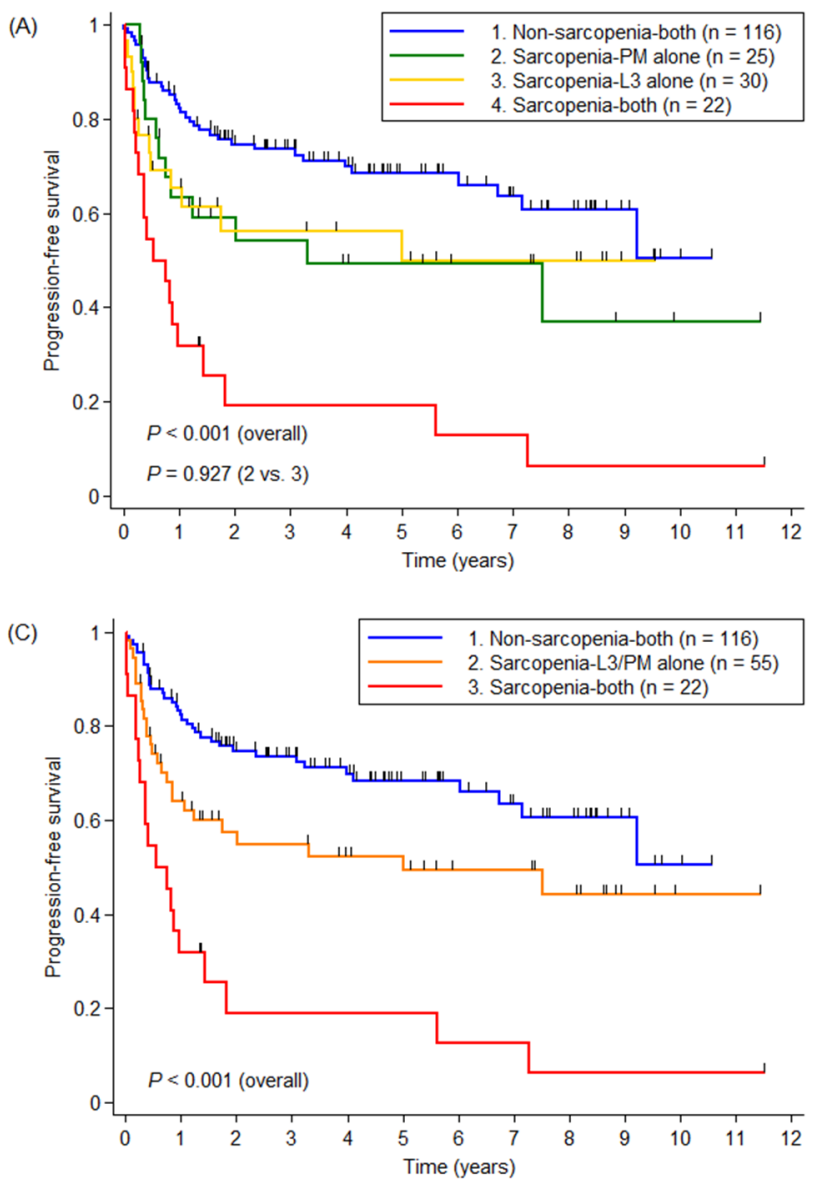

with cancer [31-33]. Similarly, the present study showed that sarcopenia was related to severe treatment-related toxicities, frequent withdrawal from treatment with consequential poor response rate, and worse survival in patients with DLBCL. Sarcopenia was also associated with factors indicative of poor nutritional status such as hypoalbuminemia and low BMI. These findings were
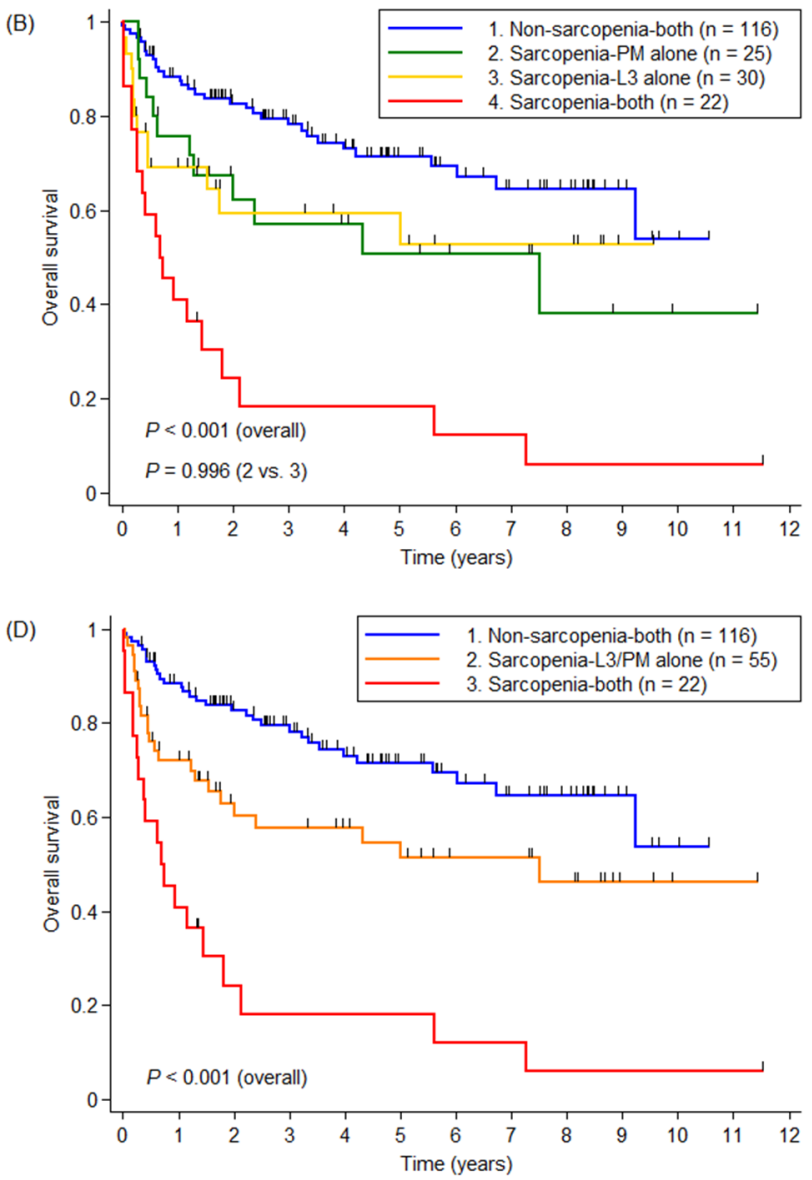

Figure 3: Kaplan-Meier curves for (A and C) progression-free survival and (B and D) OS in three and four groups divided according to sarcopenic status, respectively. Abbreviations: $\mathrm{PM}=$ pectoralis muscle. 
identical in the sarcopenia-L3 and sarcopenia-PM groups. Furthermore, there were no differences in any clinical outcome between the sarcopenia-L3 alone and sarcopeniaPM alone groups.

An international consensus for cancer cachexia proposes to use lumbar SMI determined by CT to define sarcopenia [13]. In fact, numerous studies have used L3-SMI to determine sarcopenia [24, 26-28, 33-36]. However, a recent study reported that the cross-sectional area of the pectoralis muscle determined by low-dose chest $\mathrm{CT}$ scan was significantly correlated with total body skeletal muscle mass, as measured by bioelectrical impedance analysis in healthy subjects [37]. The clinical importance of sarcopenia determined by the pectoralis muscle was assessed in respiratory tract disorders such as chronic obstructive pulmonary disease (COPD) [38] and small cell lung cancer (SCLC) [25]. COPD patients with lower pectoralis muscle area had more severe airflow obstruction, worse exercise capacity, and poorer quality of life than those with higher pectoralis muscle area [38]. Male SCLC patients with sarcopenia determined by PM-SMI were likely to have more TRM, frequent early discontinuation of treatment, and poor prognosis compared with those without sarcopenia [25]. Taken together with these previous reports, the present study more strongly supports our previous finding [29] that sarcopenia determined by PM-SMI has an adverse impact in patients with DLBCL. There is another advantage in using the pectoralis muscle to determine sarcopenia in that it can be easily measured due to its anatomical simplicity $[37,38]$.

In subsequent analyses, we found that the extent of sarcopenia could be classified more specifically when both L3- and PM-SMIs were used together to determine sarcopenia. Over $30 \%$ and $40 \%$ of the patients who met the criteria for sarcopenia determined by both L3-SMI and PM-SMI experienced TRM and had early treatment discontinuation, respectively, in the present study. These patients had a 2.5 times higher risk of death in multivariate analysis adjusted for well-known prognostic factors, compared to patients who met neither the criteria for sarcopenia determined by L3-SMI nor those determined by PM-SMI. In contrast, patients who met only one of the criteria showed features intermediate between the sarcopenia-both and non-sarcopenia-both groups in terms of treatment-related toxicity and compliance with treatment. Furthermore, their survival and level of SMIs which did not meet the criteria for sarcopenia (e.g. L3SMI in sarcopenia-PM alone group) was statistically not different with those of non-sarcopenia-both group. These findings suggest that PM-SMI is not only an alternative to L3-SMI but also has a complementary role to L3-SMI in determining sarcopenia. Several previous studies also proposed prognostic models that combine sarcopenia and other clinical factors relevant to cachexia. When a score combining sarcopenia and hypoalbuminemia replaced sarcopenia alone as a prognostic factor in DLBCL, HR for OS increased from 2.07 (sarcopenia alone) to 3.53 (higher score) [27]. Another study performed in the same cohort showed that sarcopenia and adipopenia can be integrated to predict the prognosis more accurately, when compared to the use of sarcopenia alone [39]. In metastatic renal cell cancer, sarcopenic patients with lower BMI experienced more dose-limiting toxicities from sunitinib therapy [26]. All of these findings imply that a more comprehensive approach is needed to identify cachectic patients, instead of identifying them using only sarcopenia determined by L3-SMI alone. In addition, given that chest and abdominal $\mathrm{CT}$ are routinely used in the initial assessment of patients with DLBCL, our approach using both L3 -and PM-SMIs to determine sarcopenic status is easily applicable in clinical practice.

There is a debate regarding whether sarcopenia is directly associated with poor response to anticancer therapy. Sarcopenia results in a higher plasma concentration of anticancer drugs [31,32], which may be related to better response to treatment [40]. A higher rate of pathologic CR was reported in sarcopenic patients compared with non-sarcopenic patients who were treated with neoadjuvant chemotherapy for breast cancer [41]. However, early discontinuation of treatment owing to severe toxicity may limit the efficacy of anticancer therapy in patients with sarcopenia [40]. In patients who received neoadjuvant chemotherapy for esophageal cancer, the presence of sarcopenia did not affect the rate of pathological chemotherapy response [42]. In SCLC, objective response rate was not different between sarcopenic and non-sarcopenic patients if patients who experienced early discontinuation of treatment before first response evaluation were excluded from the analysis [25]. In the present study, treatment response became worse according to the degree of sarcopenia. However, the difference in treatment response became less marked, with borderline significance after patients who discontinued treatment due to potential treatment toxicity or non-compliance were excluded from the analysis. Therefore, we suggest that intensive supportive care may be necessary to maximize and maintain the efficacy of anticancer therapy in sarcopenic patients.

The main limitation of the present study was its retrospective nature. This makes the results rather difficult to interpret because of potentially inaccurate data collection, selection bias between groups, and missing of clinically important information such as the cell-of-origin subtype. Although the relationship between the sarcopenic status and the cell-of-origin has still not been confirmed, a previous report showed that there was no association between these two factors in patients with DLBCL [27]. Another limitation is a small sample size, which may limit the generalizability of findings. Therefore, the results observed in the present study should be validated in prospective studies to overcome the problems described above. 
In conclusion, we demonstrated that both L3- and PM-SMIs can be equally used to define sarcopenia, which is associated with intolerance to R-CHOP therapy and poor prognosis in DLBCL patients. The use of only one muscle index may not be enough to define sarcopenia. Also, we expect that, when these two muscle indices are considered together to assess sarcopenic status, treatment in DLBCL patients can be more individualized.

\section{MATERIALS AND METHODS}

\section{Patients}

We retrospectively reviewed all consecutive DLBCL patients who were treated with the standard front-line R-CHOP regimen between January 2004 and October 2015 at Gyeongsang National University Hospital (GNUH). Among them, patients whose baseline CT chest and abdomen scans were available were included in this study. Exclusion criteria were as follows: 1) younger than 18 years of age, 2) front-line therapy other than the R-CHOP regimen, and 3) transformation from another type of lymphoma. This study was approved by the Institutional Review Board of GNUH.

\section{Muscle mass measurement}

CT scans were performed using a 64-detector CT (Brilliance-64; Philips Medical Systems, Best, The Netherlands) with a detector configuration of $64 \times 0.625$ $\mathrm{mm}$, a tube voltage of $120 \mathrm{kVp}$, a fixed tube current of 200 $\mathrm{mAs}$, a pitch of 0.923 , a gantry rotation time of $0.5 \mathrm{~s}$, and a smooth reconstruction (Philips ' $\mathrm{B}$ ") filter. In the chest $\mathrm{CT}$, the whole lung was scanned, from the lung apex to the diaphragm. In the abdominal CT, the whole abdomen was scanned, from the diaphragmatic dome to the pubic symphysis. The mass of the pectoralis muscle, including the pectoralis major and minor, and the muscle mass of the L3 region, including the abdominal wall, psoas, and paraspinal muscles, were measured by one radiologist with 8 years of experience.

The measurement method was as follows. First, reconstructed axial images with a $3-\mathrm{mm}$ slice thickness and 3-mm interval were analyzed at the levels of the fourth thoracic and third lumbar vertebrae using CT histogram software (the "X section" analysis tool of Advantage Window 4.4; GE Healthcare). Second, the region of interest was placed as the outermost border of muscles using freehand manual drawing. Third, the area of these muscles ranging from -29 to $100 \mathrm{HU}$ was calculated using CT histogram analysis. Then, the muscle mass was calculated as the cross-sectional area. In the case of the pectoralis muscle, the bilateral masses of the muscles were measured separately and the two values were averaged.

\section{Definition of sarcopenia}

The muscle mass area was divided by height, and the values were reported according to the region of measurement as L3-SMI and PM-SMI $\left(\mathrm{cm}^{2} / \mathrm{m}^{2}\right)$. Sarcopenia was defined as an SMI less than the muscle region- and sex-specific-cut-off values suggested by Prado et al. [34] and by our previous study [29] (L3-SMI: male, $52.4 \mathrm{~cm}^{2} / \mathrm{m}^{2}$; female, $38.5 \mathrm{~cm}^{2} / \mathrm{m}^{2}$; and PM-SMI: male, 44 $\mathrm{cm}^{2} / \mathrm{m}^{2}$; female, $31 \mathrm{~cm}^{2} / \mathrm{m}^{2}$ ). In this study, sarcopenia and non-sarcopenia were categorized as follows:

Sarcopenia-L3 - sarcopenia indexed by L3-SMI, regardless of PM-SMI (the rest are non-sarcopenia-L3);

Sarcopenia-L3 alone - sarcopenia indexed by L3SMI with a non-sarcopenic level of PM-SMI;

Sarcopenia-PM - sarcopenia indexed by PM-SMI, regardless of L3-SMI (the rest are non-sarcopenia-PM);

Sarcopenia-PM alone - sarcopenia indexed by PMSMI with a non-sarcopenic level of L3-SMI;

Sarcopenia-both - both L3-and PM-SMIs at sarcopenic levels;

Sarcopenia-L3/PM alone - sarcopenia-L3 alone or sarcopenia-PM alone;

Non-sarcopenia-both - neither L3-SMI nor PM-SMI at sarcopenic levels.

\section{Clinical data}

Clinical data of patients were independently collected using electronic medical record review by two physicians (S-I Go and G-W Lee). Any discordant data were carefully discussed among the investigators. Baseline demographics, components of IPI, and other clinical findings of DLBCL were reviewed. Hypoalbuminemia was defined as serum albumin < $3.5 \mathrm{~g} / \mathrm{dL}$ and elevated lactate dehydrogenase (LDH) as serum LDH > $225 \mathrm{IU} / \mathrm{L}$. Body mass index (BMI) was calculated by dividing the weight in kilograms by the height in square meters $\left(\mathrm{kg} / \mathrm{m}^{2}\right)$. Underweight was defined as BMI $<18.5 \mathrm{~kg} / \mathrm{m}^{2}$ according to Asian standards [43]. Treatment response was evaluated in available cases based on the revised International Working Group response criteria [44]. Treatment-related toxicity was assessed using the National Cancer Institute Common Toxicity Criteria (ver. 4.0) [45]. Treatmentrelated mortality (TRM) was defined as mortality caused directly by treatment at any time or as mortality resulting from any cause other than lymphoma progression within 30 days of the last cycle of R-CHOP. Treatment discontinuation was defined as a minimum of six cycles of R-CHOP for localized or advanced disease - and three to four cycles of R-CHOP with involved-field radiotherapy for localized disease - not being able to be performed. 


\section{Statistical analysis}

Comparisons between two groups were performed using the chi-square or Fisher's exact test for categorical variables and the Mann-Whitney U-test for continuous variables, as appropriate. For ordinal data with three categories (sarcopenia-both, sarcopenia-L3/PM alone, and non-sarcopenia-both), the chi-square test for trend and Kruskal-Wallis test were performed for categorical and continuous variables, respectively. Correlations between continuous variables were tested by Pearson's correlation coefficient. The median follow-up times were calculated by the reverse Kaplan-Meier method [46]. Overall survival (OS) was defined as the time from the beginning of treatment to death from any cause or last follow-up. PFS was defined as the time from the beginning of treatment to first progression, death from any cause, or last followup. Kaplan-Meier curves for survival data were plotted and compared via the log-rank test. Cox regression was performed to calculate the hazard ratio (HR) for death and disease progression along with its $95 \%$ confidence interval (CI). Potentially significant variables $(p<0.10)$ on univariate analysis were included in multivariate analysis. A value of $p<0.05$ was considered to be statistically significant. All statistical analyses were conducted using Stata software (ver. 14.0; Stata Corp., College Station, Texas).

\section{ACKNOWLEDGMENTS}

No funding was received for the present study.

\section{CONFLICTS OF INTEREST}

The authors declare no conflicts of interest.

\section{REFERENCES}

1. Coiffier B, Lepage E, Briere J, Herbrecht R, Tilly H, Bouabdallah R, Morel P, Van Den Neste E, Salles G, Gaulard P, Reyes F, Lederlin P, Gisselbrecht C. CHOP chemotherapy plus rituximab compared with $\mathrm{CHOP}$ alone in elderly patients with diffuse large-B-cell lymphoma. N Engl J Med. 2002; 346: 235-242.

2. Pfreundschuh $\mathrm{M}$, Trumper $\mathrm{L}$, Osterborg $\mathrm{A}$, Pettengell R, Trneny M, Imrie K, Ma D, Gill D, Walewski J, Zinzani PL, Stahel R, Kvaloy S, Shpilberg O, et al. CHOPlike chemotherapy plus rituximab versus CHOP-like chemotherapy alone in young patients with good-prognosis diffuse large-B-cell lymphoma: a randomised controlled trial by the MabThera International Trial (MInT) Group. Lancet Oncol. 2006; 7: 379-391.

3. Pfreundschuh M, Kuhnt E, Trumper L, Osterborg A, Trneny M, Shepherd L, Gill DS, Walewski J, Pettengell R, Jaeger U, Zinzani PL, Shpilberg O, Kvaloy S, et al. CHOP-like chemotherapy with or without rituximab in young patients with good-prognosis diffuse large-B-cell lymphoma: 6-year results of an open-label randomised study of the MabThera International Trial (MInT) Group. Lancet Oncol. 2011; 12: 1013-1022.

4. Pfreundschuh M, Schubert J, Ziepert M, Schmits R, Mohren M, Lengfelder E, Reiser M, Nickenig C, Clemens M, Peter N, Bokemeyer C, Eimermacher H, Ho A, et al. Six versus eight cycles of bi-weekly CHOP-14 with or without rituximab in elderly patients with aggressive $\mathrm{CD} 20+\mathrm{B}$-cell lymphomas: a randomised controlled trial (RICOVER-60). Lancet Oncol. 2008; 9: 105-116.

5. Wieringa A, Boslooper K, Hoogendoorn M, Joosten $\mathrm{P}$, Beerden T, Storm H, Kibbelaar RE, Veldhuis GJ, van Kamp $\mathrm{H}$, van Rees B, Kluin-Nelemans HC, Veeger NJ, van Roon EN. Comorbidity is an independent prognostic factor in patients with advanced-stage diffuse large B-cell lymphoma treated with R-CHOP: a population-based cohort study. Br J Haematol. 2014; 165: 489-496.

6. Merli F, Luminari S, Rossi G, Mammi C, Marcheselli L, Ferrari A, Spina M, Tucci A, Stelitano C, Capodanno I, Fragasso A, Baldini L, Bottelli C, et al. Outcome of frail elderly patients with diffuse large B-cell lymphoma prospectively identified by Comprehensive Geriatric Assessment: results from a study of the Fondazione Italiana Linfomi. Leuk Lymphoma. 2014; 55: 38-43.

7. Lin TL, Kuo MC, Shih LY, Dunn P, Wang PN, Wu JH, Tang TC, Chang H, Hung YS. The impact of age, Charlson comorbidity index, and performance status on treatment of elderly patients with diffuse large B cell lymphoma. Ann Hematol. 2012; 91: 1383-1391.

8. Jung SH, Lee JJ, Kim WS, Lee WS, Do YR, Oh SY, Kim MK, Mun YC, Shin HJ, Kwak JY, Kang HJ, Won JH, Kwon $\mathrm{JH}$, et al. Weekly rituximab consolidation following four cycles of R-CHOP induction chemotherapy in very elderly patients with diffuse large B-cell lymphoma: Consortium for improving survival of lymphoma study (CISL). Eur J Haematol. 2015; 94: 504-510.

9. Fields PA, Townsend W, Webb A, Counsell N, Pocock C, Smith P, Jack A, El-Mehidi N, Johnson PW, Radford J, Linch DC, Cunnningham D. De novo treatment of diffuse large B-cell lymphoma with rituximab, cyclophosphamide, vincristine, gemcitabine, and prednisolone in patients with cardiac comorbidity: a United Kingdom National Cancer Research Institute trial. J Clin Oncol. 2014; 32: 282-287.

10. Hainsworth JD, Flinn IW, Spigel DR, Clark BL, Griner PL, Vazquez ER, Doss HH, Shipley D, Franco LA, Burris HA 3rd, Greco FA, Sarah Cannon Oncology Research C. Briefduration rituximab/chemotherapy followed by maintenance rituximab in patients with diffuse large B-cell lymphoma who are poor candidates for R-CHOP chemotherapy: a phase II trial of the Sarah Cannon Oncology Research Consortium. Clin Lymphoma Myeloma Leuk. 2010; 10: 44-50. 
11. Shin HJ, Chung JS, Song MK, Kim SK, Choe S, Cho GJ. Addition of rituximab to reduced-dose CHOP chemotherapy is feasible for elderly patients with diffuse large B-cell lymphoma. Cancer Chemother Pharmacol. 2012; 69: 1165-1172.

12. Musolino A, Boggiani D, Panebianco M, Vasini G, Salvagni S, Franciosi V, Ardizzoni A. Activity and safety of doseadjusted infusional cyclophosphamide, doxorubicin, vincristine, and prednisone chemotherapy with rituximab in very elderly patients with poor-prognostic untreated diffuse large B-cell non-Hodgkin lymphoma. Cancer. 2011; 117: 964-973.

13. Fearon K, Strasser F, Anker SD, Bosaeus I, Bruera E, Fainsinger RL, Jatoi A, Loprinzi C, MacDonald N, Mantovani G, Davis M, Muscaritoli M, Ottery F, et al. Definition and classification of cancer cachexia: an international consensus. Lancet Oncol. 2011; 12: 489-495.

14. Das SK, Eder S, Schauer S, Diwoky C, Temmel H, Guertl B, Gorkiewicz G, Tamilarasan KP, Kumari P, Trauner M, Zimmermann R, Vesely P, Haemmerle G, et al. Adipose triglyceride lipase contributes to cancer-associated cachexia. Science. 2011; 333: 233-238.

15. Posch F, Pichler M. Inflammatory Biomarkers in Diffuse Large B-Cell Lymphoma: Time for Extending the Established Prognosis Scores? Acta Haematol. 2017; 137: 73-75.

16. Melchardt T, Troppan K, Weiss L, Hufnagl C, Neureiter D, Trankenschuh W, Schlick K, Huemer F, Deutsch A, Neumeister P, Greil R, Pichler M, Egle A. Independent Prognostic Value of Serum Markers in Diffuse Large B-Cell Lymphoma in the Era of the NCCN-IPI. J Natl Compr Canc Netw. 2015; 13: 1501-1508.

17. Prochazka KT, Melchardt T, Posch F, Schlick K, Deutsch A, Beham-Schmid C, Weiss L, Gary T, Neureiter D, Klieser E, Greil R, Neumeister P, Egle A, et al. NCCN-IPI scoreindependent prognostic potential of pretreatment uric acid levels for clinical outcome of diffuse large B-cell lymphoma patients. Br J Cancer. 2016; 115: 1264-1272.

18. Troppan KT, Melchardt T, Wenzl K, Schlick K, Deutsch A, Bullock MD, Reitz D, Beham-Schmid C, Weiss L, Neureiter D, Trankenschuh W, Greil R, Neumeister P, et al. The clinical significance of fibrinogen plasma levels in patients with diffuse large B cell lymphoma. J Clin Pathol. 2016; 69: 326-330.

19. Troppan K, Wenzl K, Pichler M, Pursche B, Schwarzenbacher D, Feichtinger J, Thallinger GG, Beham-Schmid C, Neumeister P, Deutsch A. miR-199a and miR-497 Are Associated with Better Overall Survival due to Increased Chemosensitivity in Diffuse Large B-Cell Lymphoma Patients. Int J Mol Sci. 2015; 16: 18077-18095

20. Melchardt T, Troppan K, Weiss L, Hufnagl C, Neureiter D, Trankenschuh W, Hopfinger G, Magnes T, Deutsch A, Neumeister P, Hackl H, Greil R, Pichler M, et al. A modified scoring of the NCCN-IPI is more accurate in the elderly and is improved by albumin and beta2 -microglobulin. Br J Haematol. 2015; 168: 239-245.

21. Troppan KT, Schlick K, Deutsch A, Melchardt T, Egle A, Stojakovic T, Beham-Schmid C, Weiss L, Neureiter D, Wenzl K, Greil R, Neumeister P, Pichler M. C-reactive protein level is a prognostic indicator for survival and improves the predictive ability of the R-IPI score in diffuse large B-cell lymphoma patients. Br J Cancer. 2014; 111: 55-60.

22. Prado CM, Baracos VE, McCargar LJ, Reiman T, Mourtzakis M, Tonkin K, Mackey JR, Koski S, Pituskin E, Sawyer MB. Sarcopenia as a determinant of chemotherapy toxicity and time to tumor progression in metastatic breast cancer patients receiving capecitabine treatment. Clin Cancer Res. 2009; 15: 2920-2926.

23. Tan BH, Birdsell LA, Martin L, Baracos VE, Fearon KC. Sarcopenia in an overweight or obese patient is an adverse prognostic factor in pancreatic cancer. Clin Cancer Res. 2009; 15: 6973-6979.

24. Martin L, Birdsell L, Macdonald N, Reiman T, Clandinin MT, McCargar LJ, Murphy R, Ghosh S, Sawyer MB, Baracos VE. Cancer cachexia in the age of obesity: skeletal muscle depletion is a powerful prognostic factor, independent of body mass index. J Clin Oncol. 2013; 31: 1539-1547.

25. Go SI, Park MJ, Song HN, Kang MH, Park HJ, Jeon KN, Kim SH, Kim MJ, Kang JH, Lee GW. Sarcopenia and inflammation are independent predictors of survival in male patients newly diagnosed with small cell lung cancer. Support Care Cancer. 2016; 24: 2075-2084.

26. Huillard O, Mir O, Peyromaure M, Tlemsani C, Giroux J, Boudou-Rouquette P, Ropert S, Delongchamps NB, Zerbib M, Goldwasser F. Sarcopenia and body mass index predict sunitinib-induced early dose-limiting toxicities in renal cancer patients. Br J Cancer. 2013; 108: 1034-1041.

27. Lanic H, Kraut-Tauzia J, Modzelewski R, Clatot F, Mareschal S, Picquenot JM, Stamatoullas A, Lepretre S, Tilly H, Jardin F. Sarcopenia is an independent prognostic factor in elderly patients with diffuse large B-cell lymphoma treated with immunochemotherapy. Leuk Lymphoma. 2014; 55: 817-823.

28. Nakamura N, Hara T, Shibata Y, Matsumoto T, Nakamura H, Ninomiya S, Kito Y, Kitagawa J, Kanemura N, Goto N, Shiraki M, Miyazaki T, Takeuchi T, et al. Sarcopenia is an independent prognostic factor in male patients with diffuse large B-cell lymphoma. Ann Hematol. 2015; 94: 2043-2053.

29. Go SI, Park MJ, Song HN, Kim HG, Kang MH, Lee HR, Kim Y, Kim RB, Lee SI, Lee GW. Prognostic impact of sarcopenia in patients with diffuse large B-cell lymphoma treated with rituximab plus cyclophosphamide, doxorubicin, vincristine, and prednisone. J Cachexia Sarcopenia Muscle. 2016; 7: 567-576.

30. Puppa MJ, Gao S, Narsale AA, Carson JA. Skeletal muscle glycoprotein 130's role in Lewis lung carcinoma-induced cachexia. FASEB J. 2014; 28: 998-1009. 
31. Prado CM, Lima IS, Baracos VE, Bies RR, McCargar LJ, Reiman T, Mackey JR, Kuzma M, Damaraju VL, Sawyer MB. An exploratory study of body composition as a determinant of epirubicin pharmacokinetics and toxicity. Cancer Chemother Pharmacol. 2011; 67: 93-101.

32. Mir O, Coriat R, Blanchet B, Durand JP, Boudou-Rouquette P, Michels J, Ropert S, Vidal M, Pol S, Chaussade S, Goldwasser F. Sarcopenia predicts early dose-limiting toxicities and pharmacokinetics of sorafenib in patients with hepatocellular carcinoma. PLoS One. 2012; 7: e37563.

33. Sjoblom B, Gronberg BH, Benth JS, Baracos VE, Flotten O, Hjermstad MJ, Aass N, Jordhoy M. Low muscle mass is associated with chemotherapy-induced haematological toxicity in advanced non-small cell lung cancer. Lung Cancer. 2015; 90: 85-91.

34. Prado CM, Lieffers JR, McCargar LJ, Reiman T, Sawyer MB, Martin L, Baracos VE. Prevalence and clinical implications of sarcopenic obesity in patients with solid tumours of the respiratory and gastrointestinal tracts: a population-based study. Lancet Oncol. 2008; 9: 629-635.

35. Psutka SP, Carrasco A, Schmit GD, Moynagh MR, Boorjian SA, Frank I, Stewart SB, Thapa P, Tarrell RF, Cheville JC, Tollefson MK. Sarcopenia in patients with bladder cancer undergoing radical cystectomy: impact on cancer-specific and all-cause mortality. Cancer. 2014; 120: 2910-2918.

36. Antoun S, Baracos VE, Birdsell L, Escudier B, Sawyer MB. Low body mass index and sarcopenia associated with dose-limiting toxicity of sorafenib in patients with renal cell carcinoma. Ann Oncol. 2010; 21: 1594-1598.

37. Kim YS, Kim EY, Kang SM, Ahn HK, Kim HS. Single cross-sectional area of pectoralis muscle by computed tomography - correlation with bioelectrical impedance based skeletal muscle mass in healthy subjects. Clin Physiol Funct Imaging. 2015; doi: 10.1111/cpf.12333.

38. McDonald ML, Diaz AA, Ross JC, San Jose Estepar R, Zhou L, Regan EA, Eckbo E, Muralidhar N, Come CE, Cho MH, Hersh CP, Lange C, Wouters E, et al. Quantitative computed tomography measures of pectoralis muscle area and disease severity in chronic obstructive pulmonary disease. A cross-sectional study. Ann Am Thorac Soc. 2014; 11: 326-334.

39. Camus V, Lanic H, Kraut J, Modzelewski R, Clatot F, Picquenot JM, Contentin N, Lenain P, Groza L, Lemasle E, Fronville C, Cardinael N, Fontoura ML, et al. Prognostic impact of fat tissue loss and cachexia assessed by computed tomography scan in elderly patients with diffuse large B-cell lymphoma treated with immunochemotherapy. Eur J Haematol. 2014; 93: 9-18.

40. Baracos V, Kazemi-Bajestani SM. Clinical outcomes related to muscle mass in humans with cancer and catabolic illnesses. Int J Biochem Cell Biol. 2013; 45: 2302-2308.

41. Del Fabbro E, Parsons H, Warneke CL, Pulivarthi K, Litton JK, Dev R, Palla SL, Brewster A, Bruera E. The relationship between body composition and response to neoadjuvant chemotherapy in women with operable breast cancer. Oncologist. 2012; 17: 1240-1245.

42. Yip C, Goh V, Davies A, Gossage J, Mitchell-Hay R, Hynes O, Maisey N, Ross P, Gaya A, Landau DB, Cook GJ, Griffin N, Mason R. Assessment of sarcopenia and changes in body composition after neoadjuvant chemotherapy and associations with clinical outcomes in oesophageal cancer. Eur Radiol. 2014; 24: 998-1005.

43. Consultation WHOE. Appropriate body-mass index for Asian populations and its implications for policy and intervention strategies. Lancet. 2004; 363: 157-163.

44. Cheson BD, Pfistner B, Juweid ME, Gascoyne RD, Specht L, Horning SJ, Coiffier B, Fisher RI, Hagenbeek A, Zucca E, Rosen ST, Stroobants S, Lister TA, et al. Revised response criteria for malignant lymphoma. J Clin Oncol. 2007; 25: 579-586.

45. Common Terminology Criteria for Adverse Events (CTCAE), v4.0. In.

46. Schemper M, Smith TL. A note on quantifying follow-up in studies of failure time. Control Clin Trials. 1996; 17: 343-346. 